gineers on Thursday, April 27. He gave a résumé of what had been done to discover the nature of these mysterious rays, from their properties. As a rule, engineers consider natural phenomena first of all to find out some possible utility for them. In addition, Prof. Blackett stimulated the imagination of his audience to consider all manner of possible consequences which might arise from the bombardment of the earth from outer space by some twenty particles per minute at astronomical values of electron volts. The effects of cosmic rays can be obtained, shown by experiment and recorded photographically without much difficulty and with quite simple apparatus, but calculation of these effects depends upon equations which, although easily written down, can only be approximately solved with great labour. The labour can be lightened by the use of calculating machines invented by engineers, but it is a lengthy operation. There is little exact knowledge about these rays and it is assumed that they are due to radiation from the extra-solar universe. Interesting accounts were given of the attempts that had been made on these rays by researches in the upper atmosphere, by investigations on the surface of the earth and by experiments below its crust. He said that, in the last case, the necessary apparatus had been installed in one of the underground platforms of the Holborn station of the London Passenger Transport Board, but it was found that the symmetry of the readings was effected by the presence overhead of the tunnel which carries the electric trams below Kingsway.

\section{Photography in Science and Industry}

Dr. OlaF BLOCH, chief chemist of Messrs. Ilford Limited, delivered the twenty-ninth annual May Lecture before the Institute of Metals on May 10. Dr. Bloch pointed out that the photographic emulsion consists of a finely divided suspension of one or more of the halides of silver in gelatin. There are two broad theories of development, one of which suggests that the process consists in the deposition of silver upon the latent image from the developer which has first become supersaturated, whilst the second postulates increased adsorption at the points constituting the latent image with consequent increase of developer activity in these regions. As to the latent image, we are still without definite proof of its nature. Silver bromide crystals become much more sensitive by the inclusion in them of a small amount of iodide, but the great advance which has been made in emulsion-making technique is largely due to the employment of dye-sensitizers. The second part of the lecture dealt with the applications of photography to industry. By means of the photographic emulsion our powers of observation extend far beyond the limits originally set by the senses, and. further, the grains of the emulsion are rendered developable by the passage of the fast moving particles ejected from disintegrating atoms. Investigations into the nature of cosmic rays are also being actively carried on by the aid of the photographic emulsion. For this work special emulsions have to be prepared, but all are members of a large emulsion family who serve mankind in the making of illustrations for books, in survey work, in photomicrography and photo-telegraphy, for ordinary picture making and record work, and in nearly every field of research.

\section{Sound Transmission from London Television Station}

$\mathrm{IT}_{\mathrm{T}}$ is well known that the use of ultra-short wavelengths for broadcasting purposes facilitates the attainment of a very high quality in the sound transmission on account of the extensive range of side-band frequencies which may be employed. At a meeting of the Wireless Section of the Institution of Electrical Engineers on May 3, Messrs. I. L. Turnbull and H. A. M. Clark read a paper on "The Marconi-E.M.I. Audio-Frequency Equipment at the London Television Station". This paper outlines the requirements of a high-quality sound equipment and describes the design and constructional features of the Alexandra Palace installation. The final section of the paper gives information on the overall performance of the apparatus and includes data on the frequency and harmonic distortion of the amplifier equipment. The overall frequency response from the microphone to the modulated radio frequency output to the transmitter is practically uniform from 40 cycles per second to more than 10,000 cycles per second; the second harmonic content varies up to a maximum of 0.5 per cent for full (that is, 100 per cent) modulation, while at the same modulation level the third harmonic content is about 0.1 per cent. The authors express the opinion that it is this low odd-harmonic distortion, quite as much as the extended frequency range, that is responsible for the satisfying and pleasing quality of the sound transmitted. The equipment has been in operation for a period of two years with complete satisfaction. It may be remarked in conclusion that, for some time past, it has been the practice of the British Broadcasting Corporation to transmit part of the ordinary National or Regional programme through the Alexandra Palace 'sound' transmitter, so that listeners having a television or other suitable ultrashort wave receiver may take advantage of this high-quality broadcasting station.

\section{Maternal Mortality and Industrial Welfare}

IN the course of an address delivered to the Industrial Welfare Society on April 28, the Minister of Health, Mr. Walter Elliot, stated that the provisional maternal mortality figures for 1938 have just been received and that they show a further reduction from 3.13 per 1,000 births in 1937 to 2.97 in 1938, the lowest figure ever recorded in Great Britain. Although abnormally large sums have now to be found for defence, there has been no reduction in our social services. The Government's contribution to these services and to the cost of police, roads, etc., has grown by $£ 186,000,000$ since 1925 , an expenditure that is proving an excellent investment. In addition to the new low record in maternal mortality, during the period 1927-37 the infantile mortality rate has fallen from 70 to 58 , and the tuberculosis death 